\title{
Extensive Study of the Mechanical Properties of Poly(vinyl alcohol)/ Hydroxypropyl Cellulose Copolymer Blends
}

\author{
Mohamed A. El-Hag ${ }^{1}$, Manal T. H. Moselhey ${ }^{2}$ and Osiris W. Guirguis ${ }^{1 *}$ \\ ${ }^{1}$ Department of Biophysics, Faculty of Science, Cairo University, Giza, Postcode: 12613, Egypt. \\ ${ }^{2}$ Al-Safwa High Institute of Engineering, Cairo, Egypt.
}

Authors' contributions

This work was carried out in collaboration between all authors. All authors read and approved the final manuscript.

Article Information

DOI: 10.9734/BJAST/2017/34114

Editor(s):

(1) Vyacheslav O. Vakhnenko, Division of Geodynamics of Explosion, Subbotin Institute of Geophysics, National Academy of Sciences of Ukrainian, Ukraine.

Reviewers

(1) S. Kaleem Afrough Zaidi, Aligarh Muslim University, Aligarh, India. (2) Natt Makul, Pranakorn Rajabhat University, Bangkok, Thailand. Complete Peer review History: http://www.sciencedomain.org/review-history/19347

Original Research Article

Received $14^{\text {th }}$ May 2017

Accepted $31^{\text {st }}$ May 2017

Published $5^{\text {th }}$ June 2017

\section{ABSTRACT}

Many researches have been devoted for studying poly(vinyl alcohol) (PVA) and hydroxypropyl cellulose (HPC) and their blends as important promising biomaterials. In the present work, thin films of pure PVA, pure HPC and their PVA/HPC blends were prepared using the solution casting method. The mechanical properties of the prepared thin films such as stress-strain curve, tensile modulus and tensile strength as well as elongation at break were investigated. The obtained results show that there is an increase in the elastic range and decrease in the hardness of the resulting blends by increasing the concentration of HPC due to the different molecular morphology. In addition, the range in which it would responds elastically to external stress was decreased to some extent.

Keywords: Polymer blends; Poly(vinyl alcohol); hydroxypropyl cellulose; PVA/HPC copolymer blends; mechanical properties. 


\section{INTRODUCTION}

Synthetic polymers received increasing attention in industrial, biomedical and pharmaceutical applications.

Poly(vinyl alcohol) (PVA) is one of the effective and most utilized synthetic polymers as promising biomaterials due to its specific structure and properties. PVA is a nontoxic, water-soluble polyhydroxy polymer, stable hydrogel, biodegradable semicrystalline polymer, biocompatible, has chemical resistance and has good thermal stability [1,2]. According to its chemical and physical properties, PVA was used in many applications in the fields of: electronics automobile industry, paper coating, flexible water-soluble packaging films, textile sizing, cosmetic, adhesive and construction [3,4]; medicine to replace diseased or damaged articular cartilage, drug delivery, contact lenses, corneal implants, substitutes for skin, tendons, artificial pancreas, ligaments and bone-like apatite formation [5-9]. Williams was found that PVA was used as an artificial vascular graft due to its mechanical strength [10]. In addition, PVA possesses similar water content to natural articular cartilage and calls Salumedica, Atlanta, GA (Salubria ${ }^{\mathrm{TM}}$ ).

There are several manners to modify the properties of the polymer, viz. blending, curing and grafting, as well as derivatization. Blending is the physical mixture of polymers to obtain and enhance the requisite properties and also for developing pharmaceutical industries and biomedical applications of polymeric materials $[11,12]$. According to the specific structure and properties of PVA was widely used as a host material for blends [13] and nanocomposites $[14,15]$. Also, the possibility to tailoring PVA properties was increased by blending it with other compatible synthetic and/or natural polymers. PVA can be blended with cellulose, e.g., hydroxypropyl cellulose (HPC) and hydroxypropyl methyl cellulose (HPMC) [16].

Cellulose is the most abundant biomass material in nature occurring polymer, and possesses some promising properties, such as colorless, odorless, nontoxic solid polymer, has mechanical strength, hydrophilicity, biocompatibility, biodegradability, relative thermal stability, high sorption capacity and alterable optical appearance [17-19]. Due to these promising properties, cellulose is acceptable from the environmental point of view and was applied in different fields such as drug delivery, biomaterial, water treatment, thickener, stabilizer, separation, package, optical media, biomembrane, adsorption and was used to fabricate "smart" materials $[18,20]$.

Hydroxypropyl cellulose (HPC) is a polymer soluble in water and in polar organic solvents. HPC belongs to the group of cellulose ethers. For many years ago, HPC was used as paper of conservators as glue and sizing material [21]. HPC is a colorless, odorless, nontoxic, hydrophilicity, biocompatibility, biodegradability and has thermal stability. HPC was applied in different pharmaceutical and biomedical fields. HPC was used: for production of time controlled delivery systems, for artificial tears, as a topical ophthalmic protectant and as a lubricant for artificial eyes [22] as a disintegrants, as a binder of making tablets [23], as an emulsion stabilizer with $\mathrm{E}$ number E463 and as a sieving matrix for DNA separations by capillary and microchip electrophoresis [24]. On another hand, due to HPC solubility in water and temperatureresponsive property, "Smart" materials based on HPC were also studied [25].

The purpose of the present work was to quantify and enhance the functional mechanical properties of PVA biomaterial. Thin films of neat PVA, HPC and their PVA/HPC blends were prepared using the solution cast method. The mechanical properties such as stress-strain curve, tensile modulus and tensile strength as well as elongation at break of the prepared blends were investigated.

\section{EXPERIMENTAL DETAILS}

\subsection{Materials and Sample Preparation}

Poly(vinyl alcohol) (PVA) granules with a molecular weight $125 \mathrm{~kg} / \mathrm{mol}$ and with a degree of $99 \%$ was supplied from El-Nasr Company, Cairo, Egypt. Hydroxypropyl cellulose powder (HPC; Pharma-coat 606) with molecular weight $95 \mathrm{~kg} / \mathrm{mol}$ was supplied from Shin Etsu Chemical Co., Tokyo, Japan. The experimental materials were used as received.

A film casting method was used to prepare thin films of the neat PVA, neat HPC and their PVA/HPC blends as previously reported [26,27]. Complete solutions of weighted amounts of PVA granules and HPC powder in double distilled water, separately as well as mixed together using a magnetic stirrer at $50^{\circ} \mathrm{C}$ water bath for $2 \mathrm{~h}$ 
were obtained to prepare thin films of neats (PVA and HPC) and their PVA/HPC blends with three different weight percentages $(80 / 20,50 / 50$ and $20 / 80 \mathrm{wt} / \mathrm{wt} \%$ ). The complete dissolutions were cast onto stainless steel Petri dishes of $10 \mathrm{~cm}$ diameter. Then the Petri dishes were kept at room temperature (about $25^{\circ} \mathrm{C}$ ) for 7 days until the solvent was completely evaporated. Thin films of thickness about $0.1 \mathrm{~mm}$ were formed and were kept in desiccators to avoid moisture.

\subsection{Experimental Technique}

A Zwick Mechanical Testing Machine model Z010 (made in Germany) was used to measure the mechanical properties of the prepared pure PVA, pure HPC and their PVA/HPC blends thin films. The tensile modulus, tensile strength and elongation at break were investigated. The film thickness and the dimensions of the test specimens for all samples were kept constant. From the obtained cast films, the tensile test samples were prepared by cutting pieces with a gage dimension of $100 \times 10 \times 0.1 \mathrm{~mm}^{3}$. For reproducibility, at least five specimens for each film sample were tested under the same conditions and the average value was taken.

\section{RESULTS AND DISCUSSION}

Fig. 1 shows the stress-strain curves for the thin films of pure PVA, pure HPC and their PVA/HPC blends. It was clear from the figure that, significant differences between the blend films were observed in comparison with the neat films. Linear dependence of the strain with increasing stress within the elastic limit up to a certain value of stress was detected. Regions of plastic deformation were followed where the strain increases even at constant stress with very narrow elastic limit for pure HPC. In addition, for pure PVA sample, the maximum stress was the highest value (about 63.0 MPa) which is in agreement with that reported previously in the literature $[28,29]$, whereas that for the pure HPC sample was the lowest value (about 9.6 MPa). The behavior of the stress-strain curves are similar for all blends and the maximum stress values for the PVA/HPC blends decreased gradually with increasing the concentration of HPC up to $80 \mathrm{wt} \%$ and in between the neat PVA and HPC values, i.e., ranging from about 50 to $22 \mathrm{MPa}$.

The maximum stress was plotted as a function of HPC weight percent in Fig. 2. It was shown from the figure that the maximum stress value decreases with increasing the HPC concentration towards the neat HPC value and a nearly straight line relationship was detected (red solid line). It was also noted from the curves of Fig. 1 that, the initial modulus value of the neat PVA decreases with increasing the HPC weight \% up to $80 \mathrm{wt} \%$. The obtained data noticed that, by increasing HPC concentration the elastic range was increased and the hardness was reduced of the resulting blends. These variations may be attributed to moleacular morphology which indicate that a decrease in crytallinity and crosslinking in the PVA polymeric network $[29,30]$.

The variation in the tensile modulus of pure PVA, pure HPC and their blends thin films were shown in Fig. 3. The data represented in the figure indicate that the tensile modulus value decreases in step-wise manner as the concentration of HPC increases. Moreover, pure PVA has the highest value of tensile modulus while pure HPC has the lowest one. The tensile modulus value of the pure PVA is in agreement with that previously reported [31], Very high significant variation in the tensile modulus for the three blends and their values are in between PVA and HPC values. The tensile modulus decreased by about $65 \%$ for the blend with 50 wt $\%$ HPC contents and no significant decrease for higher HPC concentration (80 wt\%) was detected. The observed variations may support the idea of the inverse relation between the concentration of HPC and the hardness of the resulting blend.

Fig. 4 shows the variation of the tensile strength of neat PVA and HPC and their blends. The results show that the tensile strength value decreases by about $66 \%$ with increasing the concentration of HPC up to $80 \%$ in comparison with the value of the neat PVA. In addition, the tensile strength values decrease for the three blends and there variations were high significant. The obtained results indicate that all blends have lower tensile modulus and tensile strength values than those of the neat PVA value and, on other hand, higher than those of the neat HPC value. The obtained variation may be due to that good dispersion of HPC in the PVA polymer matrix and, also, due to the strong interatomic interactions which causes formation of new bonds.

Fig. 5 represents the variation of the elongation at break (\%) for the thin films of neat PVA, neat HPC and their PVA/HPC blends. It was shown from the figure that, the elongation at break was reduced by about $7 \%$ for PVA/HPC blend of 20 
wt\% HPC, then slight increases by about $0.2 \%$ for PVA/HPC blend of $50 \mathrm{wt} \%$ HPC and continuous increase with PVA/HPC blend of $50 \mathrm{wt} \%$ HPC by about $11 \%$. The elongation at break of pure HPC thin film shows the highest value.
The percentage changes in the parameters under investigation have been calculated and were tabulated in Table 1 in order to provide a simpler method for representing and understanding for how HPC may affect the mechanical properties of PVA.

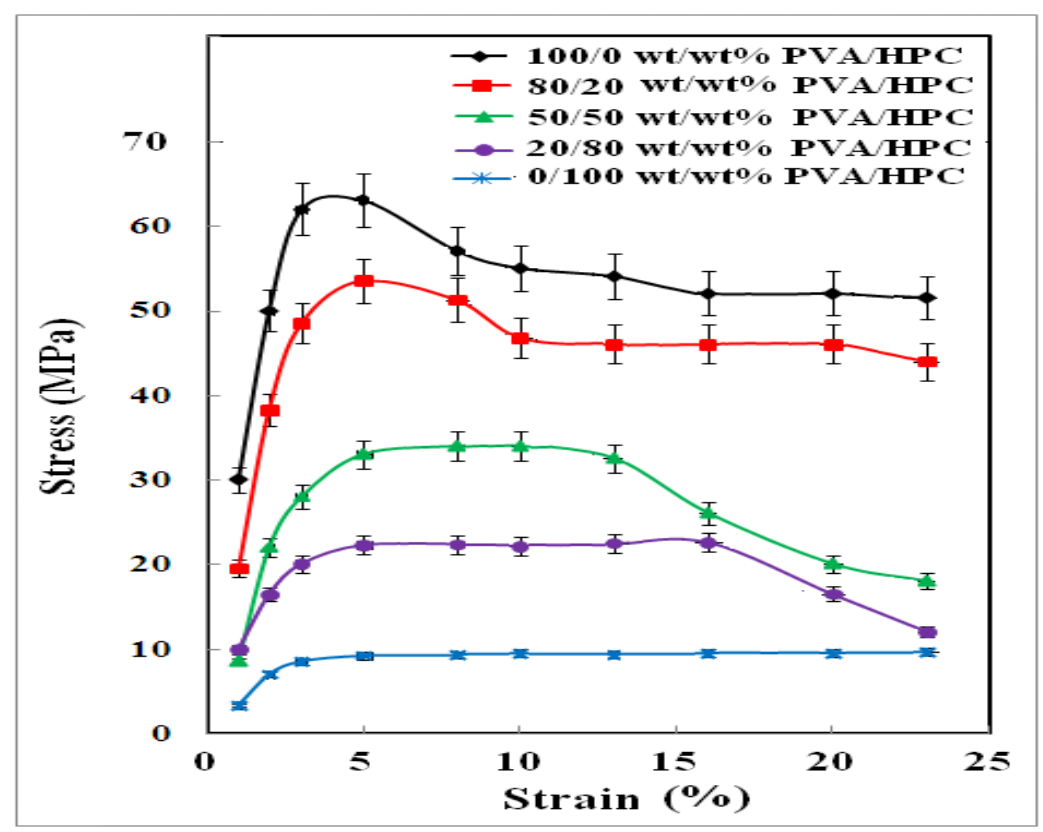

Fig. 1. Stress-strain curves for PVA, HPC and their PVA/HPC blends thin films

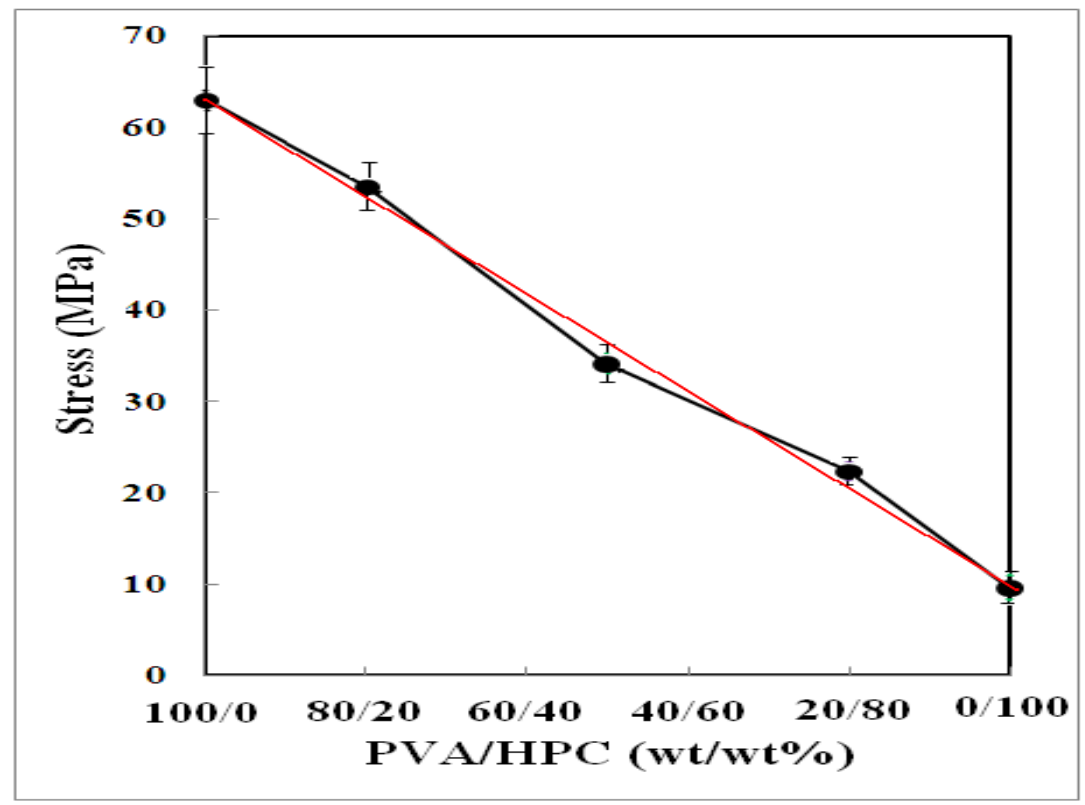

Fig. 2. Relationship between the maximum stress and HPC concentration 


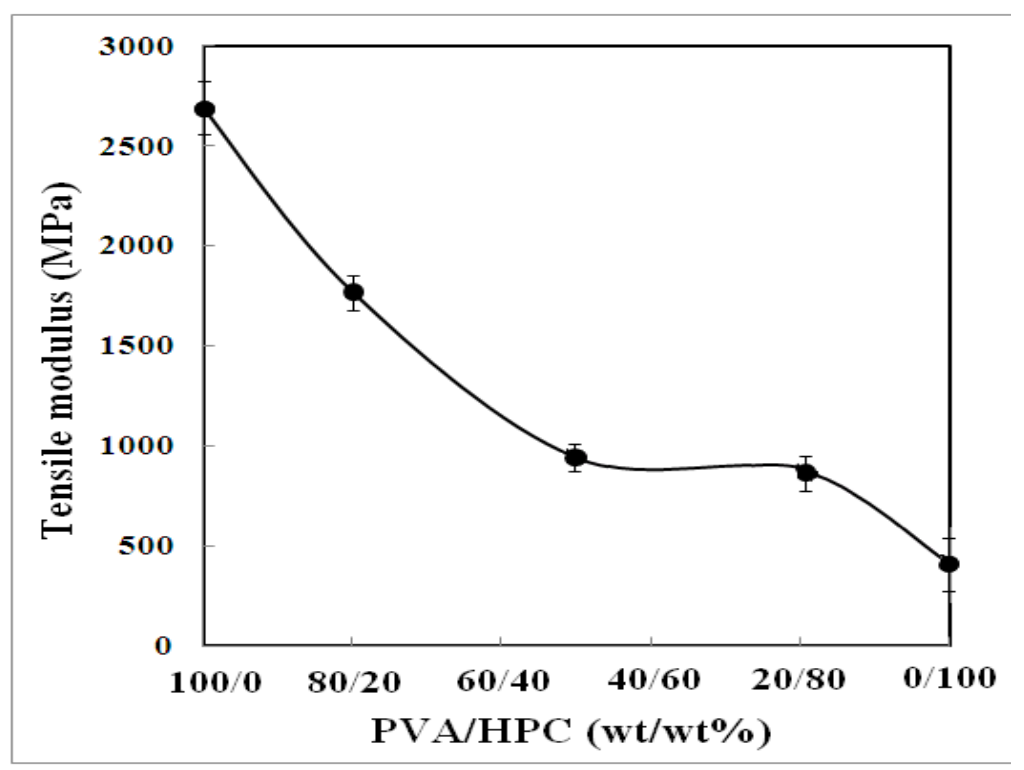

Fig. 3. Variations in the tensile modulus of PVA and HPC and their PVA/HPC blends thin films (average of five tests)

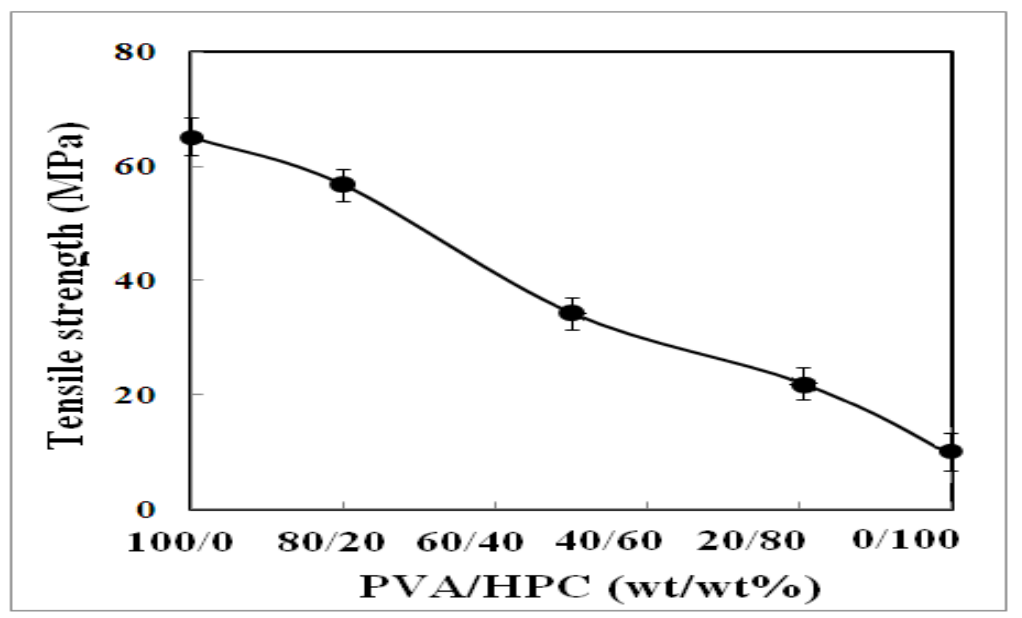

Fig. 4. Variations in the tensile strength of PVA and HPC and their PVA/HPC blends thin films (average of five tests)

Table 1. The percentage changes of tensile modulus $(\Delta \mathrm{E} \%)$, tensile strength $\left(\Delta \mathrm{T}_{s} \%\right)$ and elongation at break $(\Delta \varepsilon \%)$ of PVA/HPC blends with respect to the neat PVA

\begin{tabular}{llll}
\hline $\begin{array}{l}\text { PVA/HPC } \\
\text { blend (wt/wt\%) }\end{array}$ & $\boldsymbol{\Delta E} \%$ & $\boldsymbol{\Delta T}_{\mathbf{s}} \%$ & $\begin{array}{l}\boldsymbol{\Delta} \boldsymbol{\varepsilon} \\
\%\end{array}$ \\
\hline $0 / 100$ & - & - & - \\
$80 / 20$ & -34.3 & -13.0 & -7.0 \\
$50 / 50$ & -64.9 & -47.5 & 0.2 \\
$20 / 80$ & -67.4 & -66.0 & 11.4 \\
\hline
\end{tabular}

The data observed in the table noticed that there is considerably decrease in the tensile modulus and the tensile strength values with increasing HPC concentration up to $80 \mathrm{wt} \%$. These results support the idea of that PVA/HPC blend would reduce the elastic range, as well as, the hardness of the polymer network but with increasing its compliance. As it has been reported, mechanical properties were controlled largely by the interatomic forces or the interatomic potential energy. 


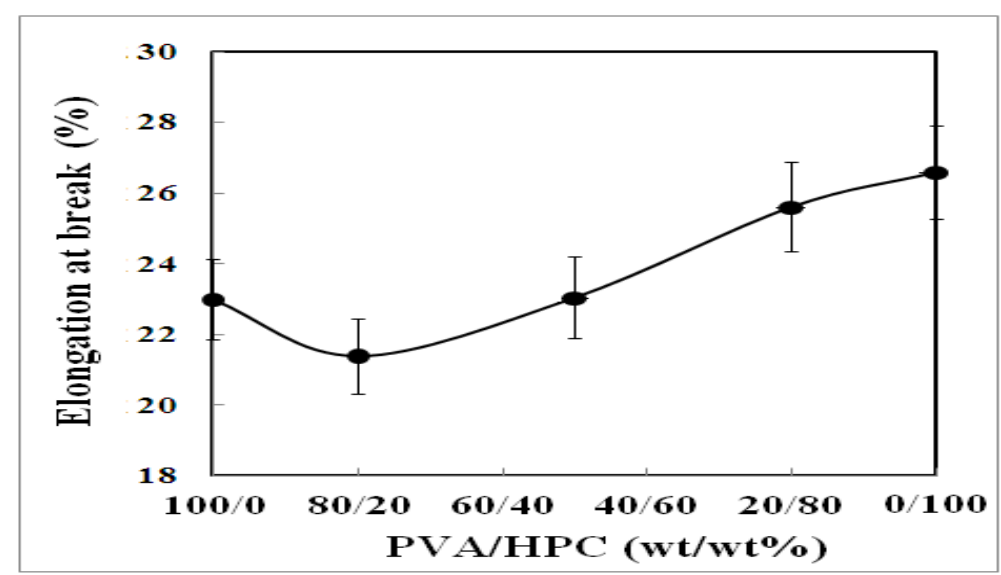

Fig. 5. Variations in the elongation at break (\%) of PVA and HPC and their PVA/HPC blends thin films (average of five tests)
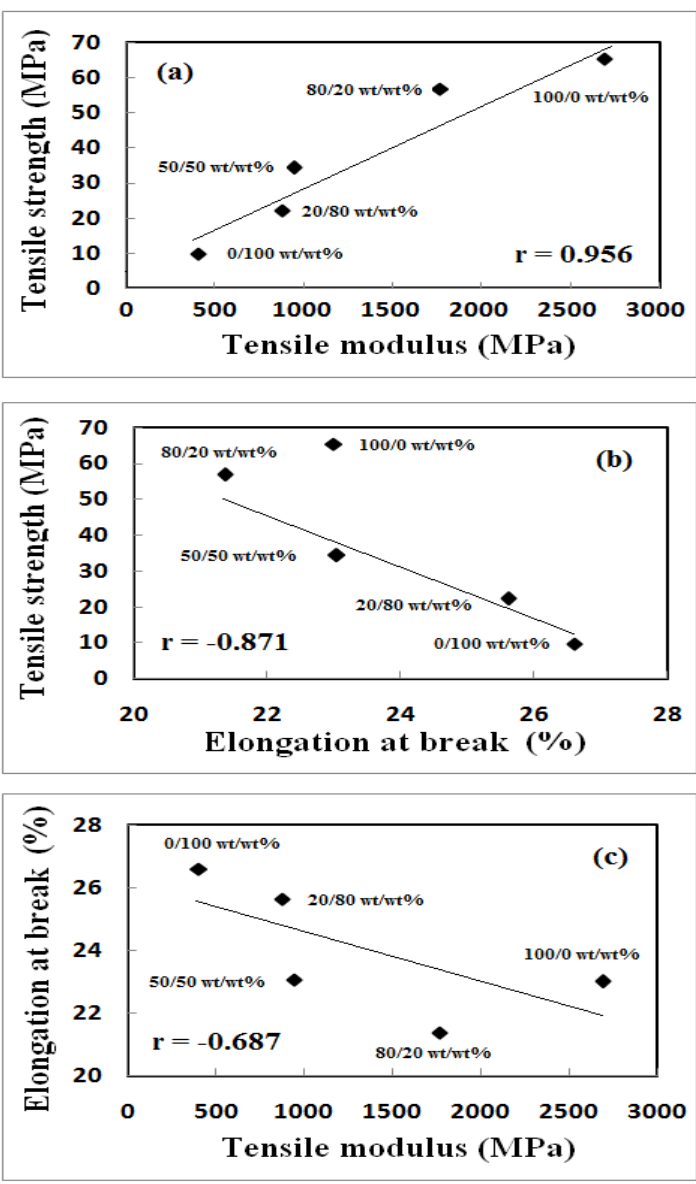

Fig. 6. Graphic representation of Pearson's correlation between: (a) Tensile strength and tensile modulus, (b) tensile strength and elongation at break and (c) elongation at break and tensile modulus
From Fig. 6, the correlation analysis results indicated positive relationship between tensile strength and tensile modulus $(r=0.956)$ (Fig. 6a), while the correlations the tensile strength with elongation at break $(\%)(r=-0.871)$ (Fig. 6b), and elongation at break (\%) with tensile modulus ( $r=-0.687$ ) (Fig. $6 \mathrm{c})$ are negative.

\section{CONCLUSIONS}

The data obtained here showed that increasing the concentration of HPC in PVA/HPC blend produce pronounced changes in the mechanical properties of PVA. Both tensile modulus and tensile strength of PVA were improved by increasing HPC concentration. These changes may be attributed to the dispersion of HPC within PVA matrix and their interatomic interactions that occurred.

\section{COMPETING INTERESTS}

Authors have declared that no competing interests exist.

\section{REFERENCES}

1. Huang S, Cen X, Zhu H, Yang Z, Yang Y, Tjiu WW, Liu T. Facile preparation of poly(vinyl alcohol) nanocomposites with pristine layered double hydroxides. Materials Chemistry and Physics. 2011; 130:890-6.

2. Han YU, Lee CG, Park JA, Kang GK, Lee I, Kim SB. Immobilization of layered double hydroxide into polyvinyl alcohol/alginate hydrogel beads for phosphate removal. 
Environmental Engineering Research. 2012;17:133-8.

3. Soundararajah QY, Karunaratne BSB, Rajapakse RMG. Mechanical properties of poly(vinyl alcohol) montmorillonite nanocomposites. Journal of Composite Materials. 2010;44:303-11.

4. Qin Q, Liu Y, Chen SC, Zhai FY, Jing XK, Wang YZ. Electrospinning fabrication and characterization of poly(vinyl alcohol)/layered double hydroxides composite fibers. Journal of Applied Polymer Science. 2012;126:1556-68.

5. Zheng-Qiu G, Jiu-Mei X, Xiang-Hong Z. The development of artificial articular cartilage - PVA-hydrogel. Bio-Medical Materials and Engineering. 1998;8:75-81.

6. Peppas NA, Keys KB, Torres-Lugo M, Lowman AM. Poly(ethylene glycol)containing hydrogels in drug delivery. Journal of Controlled Release, 1999;62:817.

7. Lee KY, Mooney DJ. Hydrogels for tissue engineering. Chemical Reviews. 2001; 101:1869-79.

8. Stammen JA, Williams S, Ku DN, Guldberg RE. Mechanical properties of a novel PVA hydrogel in shear and unconfined compression. Biomaterials. 2001;22:799806.

9. Tong X, Zheng JG, Lu YC, Zhang ZF, Cheng HM. Swelling and mechanical behaviors of carbon nanotube/poly (vinyl alcohol) hybrid hydrogels. Materials Letters. 2007;61:1704-6.

10. Williams S. Mechanical testing of a new biomaterial for potential use as a vascular graft and articular cartilage replacement. MS Thesis, Georgia Institute of Technology; 1998.

11. Çaykara T, Demirci S. Preparation and characterization of blend films of poly(vinyl alcohol) and sodium alginate. Journal of Macromolecular Science, Part A: Pure and Applied Chemistry. 2006;43:1113-21.

12. Kulkarni RV, Sa B. Electroresponsive polyacrylamide-grafted-xanthan hydrogels for drug delivery. Journal of Bioactive and Compatible Polymers. 2009;24:368-84.

13. Korbag I, Saleh SM. Studies on mechanical and biodegradability properties of PVA/lignin blend films. International Journal of Environmental Studies. 2016; 73:18-24.

14. Cheng-an T, Hao Z, Fang W, Hui Z, Xiaorong Z, Jianfang W. Mechanical properties of graphene oxide/polyvinyl alcohol composite film. Polymers \& Polymer Composites. 2017;25:11-16.

15. Nawaz K, Ayub M, Ul-Haq N, Khan MB, Bila M, Niazi K, Hussain A. The effect of large area graphene oxide (LAGO) nanosheets on the mechanical properties of polyvinyl alcohol. Journal of Polymer Engineering. 2016;36:399-405.

16. Sakellariou P, Hassan A, Rowe RC. Phase separation and polymer interactions in aqueous poly(vinyl alcohol)/hydroxypropyl methylcellulose blends. Polymer. 1993; 34:1240-8.

17. Tosh B, Routray CR. Grafting of cellulose based materials: A review. Chemical Science Review and Letters. 2014;3:74-92.

18. Qiu X, Hu S. "Smart" materials based on cellulose: A review of the preparations, properties and applications. Materials. 2013;6:738-81.

19. Klemm D, Philipp B, Heinze T, Heinze U, Wagenknecht W. Comprehensive cellulose chemistry. Fundamentals and analytical methods. WILEY-VCH Verlag $\mathrm{GmbH}$, Weinheim, Germany. 1998;1.

20. Sannino A. Demitri C, Madaghiele M. Biodegradable cellulose-based hydrogels: Design and applications. Materials. 2009; 2:353-73.

21. Hofenk-de Graaff J. In central research laboratory for objects of art and science. Gabriel Metsustroat and 1071 EA, Amsterdam; 1981.

22. Eaga CM, Kandukuri JM, Allenki V, Yamsani MR. In-situ gels -a novel approach for ocular drug delivery. Der Pharmacia Lettre. 2009;1:21-33.

23. Ishikawa T, Mukai B, Shiraishi S, Utoguchi $\mathrm{N}$, Fujii M, Matsumoto MA, Watanabe U. Studies of rapidly disintegrating tablet prepared by direct compression method. Chemical and Pharmaceutical Bulletin. 2001;49:134-9.

24. Sanders JC, Breadmore MC, Kwok YC, Horsman KM, Landers JP. Hydroxypropyl cellulose as an adsorptive coating sieving matrix for DNA separations: Artificial neural network optimization for microchip analysis. Analytical Chemistry. 2003; 75:986-94.

25. Liao Q, Shao Q, Qiu G, Lu X. Methacrylic acid-triggered phase transition behavior of thermosensitive hydroxypropylcellulose. Carbohydrate Polymers. 2012;89:1301-4.

26. Suhas N, Rupali S, Mallikarjuna S, Inayat $\mathrm{P}$, Anand $\mathrm{D}$. Controlled release nateglinide tablets using $\mathrm{Na}-\mathrm{CMC}$ and HPMC 
hydrophilic polymer. Research Journal of Pharmacy and Technology. 2010;3:87-91.

27. El-Zaher NA, Guirguis OW. Thermal and structural properties of poly(vinyl alcohol) doped with hydroxypropyl cellulose. Journal of Applied Polymer Science. 2005; 96:1914-23.

28. Mbhele H, Salemane MG, van Sittert CGC, Nedeljkovic JM, Djokovic V, Luyt AS. Study of sago starch-CdS nanocomposite films: Fabrication, structure, optical and thermal properties. Chemistry of Materials. 2003;15:5019-24.

29. Fukumori T, Nakaoki T. Significant improvement of mechanical properties for polyvinyl alcohol film prepared from freeze/thaw cycled gel. Open Journal of Organic Polymer Materials. 2013;3:1106.

30. Krumova M, Lopez D, Benavente R, Mijangos C, Perena, JM. Effect of crosslinking on the mechanical and thermal properties of poly(vinyl alcohol). Polymer. 2000;41:9265-72.

31. Konidari MV, Papadokostaki KG, Sanopoulou M. Moisture-induced effects on the tensile mechanical properties and glass-transition temperature of poly(vinyl alcohol) films. Journal of Applied Polymer Science. 2011;120:3381-6.

(c) 2017 El-Hag et al.; This is an Open Access article distributed under the terms of the Creative Commons Attribution License (http://creativecommons.org/licenses/by/4.0), which permits unrestricted use, distribution, and reproduction in any medium, provided the original work is properly cited.

Peer-review history:

The peer review history for this paper can be accessed here: http://sciencedomain.org/review-history/19347 